\title{
Tax revenue accruing from the commercialization of research findings as an indicator for economic benefits of government financed research
}

\author{
Simon P. Forster and Stefan Seeger* \\ Business Chemistry Group, Department of Chemistry, University of Zurich, \\ Winterthurerstrasse 190, 8057 Zurich, Switzerland \\ *Corresponding author.Email: sseeger@chem.uzh.ch
}

\begin{abstract}
In this article, we propose the use of tax payments accruing from the commercialization of research findings as a measure of research benefits complementing the existing range of evaluation tools. We place this novel approach to assess the economic returns to publicly funded research in the context of previous studies and highlight its advantages. The application of our method over a long period is demonstrated with the example of saccharin, which was discovered in the context of a curiosity-driven fundamental research project. In our study, we focused on Monsanto's commercial saccharin production finding notable returns.
\end{abstract}

Keywords: saccharin; fundamental research; curiosity-driven research; commercialization tax-based approach; case study.

\section{Introduction}

It is now well established that research-including notably curiosity-driven fundamental research-is important for the wealth and economic growth of a country (Advisory Council on Scientific Policy 1960; Byatt and Cohen 1969; Kay and Llewellyn Smith 1985; Pavitt 1991; Roessner 1993; Klevorick et al. 1995; Narin et al. 1997; Gulbrandsen 2009; Vincett 2010). The impacts of research on the economy are multidimensional and sometimes occur through complex and indirect pathways (van Raan 2000; Martin and Tang 2006). They include the creation of new knowledge in its broadest sense (Hoppe and Pfähler 2001; Scott et al. 2002; Geiger 2004) - influencing, e.g. corporate research (Balconi et al. 2010) or productivity (Link 1996) - the introduction of advanced instrumentation (Price 1984), public health benefits (Byatt and Cohen 1969; Martin and Tang 2006), the output of trained graduates (David et al. 1992; Zellner 2003), the formation of social networks or 'invisible colleges' (Price 1984), and of course the commercialization of research findings and discoveries (Gulbrandsen 2009). These different types of economic impacts of research have received considerable attention in numerous assessment studies, which have been conducted in the past for both public accountability reasons and to improve future policy decisions [a useful overview can be found in Marjanovic et al. (2009)]. In general, the majority of these studies reported considerable returns on investment for the country funding the research, some of them exceeding returns on stock (Arnold and Balázs 1998).

However, there is no generally applicable method that can take into account all the diverse impacts of research introduced above at the same time (Arnold and Balázs 1998; Tassey 2003). By necessity, previous studies have focused on evaluating selected impacts of research. To complement the existing range of techniques, we present in Section 2, a novel approach to assess the economic returns to publicly funded research and place it in context of previous evaluation studies. We propose the 
use of tax payments accruing from the commercialization of research findings-largely neglected by existing studies - as a measure of the benefits to a particular country. The application of our approach is not limited to a specific kind of research (fundamental or applied, curiosity-driven or mission-oriented), as long as it led to identifiable tax revenue.

In Section 3, we demonstrate the application of our approach in detail with an example of a curiosity-driven fundamental research project, which serendipitously led to a marketable product-saccharin. As the sweetener was discovered already in 1878 , the case offered a unique long-term valuation perspective, which is rarely provided in the literature. The results of the calculations and the implications for the applicability of our method are discussed in Section 4. In the final section, we highlight the conclusions that can be drawn from our case study, and we describe how our method could be implemented in future evaluation studies.

Besides serving as an example for the implementation of our approach, the saccharin case in itself is worth considering, as it presents further evidence that curiosity-driven academic fundamental research can lead to successful commercial ventures and to direct paybacks on the initial research investment. The history of the case starts in 1876 when Ira Remsen was appointed as professor of chemistry at the newly founded Johns Hopkins University in Baltimore, MD - the first university in the USA to define research as the core of its educational pursuits (Hannaway 1976). His research interests lay in the synthesis of novel coal-tar derivatives to work out fundamental chemical principles without having particular applications in mind (Noyes and Norris 1932; Getman 1980), and his commitment to curiosity-driven research is welldocumented (Hannaway 1976; Kauffman and Priebe 1978; Roth and Lück 2011). In the course of one research project, his fellow Constantin Fahlberg synthesized 'benzoic sulfinide' in 1878, which was accidentally found to taste remarkably sweet. Importantly, Fahlberg did not neglect this finding as unwanted 'by-product' of his research but instead went on to commercialize what he called saccharin in the mid-1880s by founding a company in Germany (Beyer 2005). The large-scale manufacturing of saccharin in the USA began when John F. Queeny in 1901 built up his company Monsanto in St. Louis, MO, specifically for the production of saccharin (Forrestal 1977).

The circumstances of the discovery and the entrepreneurial, regulatory, and wartime influences on the fate of saccharin as Monsanto's first product are described elsewhere (Forster and Seeger in preparation a, in preparation b). References to other relevant literature on saccharin are provided therein as well. We have extended the information provided by these publications with data obtained from archival material-an extensive and largely untapped source of data for valuations - to compile a solid foundation for our calculations of the tax revenue and ultimately of the benefits accruing from Monsanto's saccharin operations.

Saccharin was chosen as a case because it allowed for a reasonable demonstration of our approach in a comparatively well-defined setting. For instance, it was suitable to limit the calculations of the tax revenue to Monsanto, which produced saccharin from 1901-72, as, firstly, its corporate records are accessible through the Washington University in St. Louis; secondly, it was the first US company to produce the sweetener; thirdly, it was once the World's largest producer of saccharin; fourthly, the discovery of saccharin at a US university suggested the consideration of a US company.

\section{Method and scope}

The idea to evaluate government financed research is of course not new, be it for general quality control, for assessing the influences of policy measures, or for public accountability due to the presence of many competing and justifiable areas requiring public expenditure such as health care, education, or energy (Luukkonen-Gronow 1987; Arnold and Balázs 1998). As the focus of the present article lies on the economic impacts of research, we do not discuss in detail widely used methods such as peer review and bibliometrics, which are established in assessments of the scientific quality of research but normally cannot be used to account for its economic impacts (Luukkonen-Gronow 1987; Arnold and Balázs 1998; Schmoch and Schubert 2009). Instead, we focus on studies that were conducted for the latter purpose. As mentioned before, Marjanovic et al. (2009) provide a useful overview of evaluation studies including a historical perspective. The following paragraphs thus serve for illustrating purposes only, raising no claim to completeness.

Although the amount of publications dealing with the economic impacts of (publicly funded) research is increasing, only a minority of them presents numerical estimates for the alleged returns. For instance, some of the seminal studies in the field do not include a calculation of economic returns. This is the case with Jewkes et al. (1969) who analyzed more than 50 inventions - including several cases stemming from corporate R\&D departments-regarding the environment of their emergence (the first edition was published already in 1958). The situation looks similar in a very famous study, commonly known by the name TRACES, which was commissioned by the National Science Foundation and conducted by the IIT Research Institute (1968).

The paper by Griliches (1958) is still one of the most famous publications actually featuring the calculations of return rates. To estimate the input parameters, Griliches relied mainly on survey data. Also using surveys, 
Mansfield (1991) attempted to calculate the social rate of return from worldwide investments in academic research. Later, Link and Scott (2004) used estimates obtained from interviews to assess the benefits and costs related to a specific R\&D program.

The returns on (bio-)medical research were studied by Weisbrod (1971) and Fudenberg (1973), using their own estimations and official data. Furthermore, the case study by Chien and Silverstein (1993) is notable because the authors applied multipliers provided by the Department of Commerce to extend their calculations of the benefits of monoclonal antibodies to secondary impacts, such as employment at companies in the supply chain. The framework by Murphy and Topel (2003), in contrast, was based on theoretical assumptions on the benefits accruing from extensions of the life cycle consumptions and the expected utilities of individuals.

Econometric studies represent a further important approach to measure the returns on research investments. Lichtenberg and Siegel (1991), for instance, used a framework based on total factor productivity to examine the association between $\mathrm{R} \& \mathrm{D}$ and productivity growth with longitudinal microdata. A comprehensive review of econometric studies is provided by Hall et al. (2009).

Despite the individual attractiveness of each method applied in the studies discussed above, none of these approaches can single-handedly take into account all the diverse impacts of research, as mentioned in Section 1. Additionally, more or less severe disadvantages and biases are associated with the application of these techniques. Survey-based studies, for instance, may be subject to flaws resulting from low response rates, untruthful respondents, and subjective answers (Martin and Salter 1996: 13; Salter and Martin 2001: 513; Marjanovic et al. 2009), and it is unclear whether the views expressed by participants should really be used as a measure for economic benefits (Luukkonen-Gronow 1987). Econometric studies, on the other hand, rely on assumptions that may be unrealistic or unsuited to relate benefits to research projects (Salter and Martin 2001: 513); e.g. it is a gross oversimplification to assume that companies have invariant production functions and that every innovation impacts existing production functions instead of creating new ones (Link 1996: 337; Martin and Salter 1996: 17; Georghiou and Roessner 2000: 661). Further, these studies suggest that intensifying scientific research is profitable for the economy, but they do not differentiate between specific research areas (Arnold and Balázs 1998: 2).

In the following, we suggest the consideration of tax payments accruing from the commercialization of research outcomes as a measure to complement the existing range of techniques to assess the economic returns to R\&D. Our approach can be applied to value research projects, which led or probably will lead to identifiable tax-relevant impacts arising from new product introductions or economies owing to new knowledge. To obtain meaningful results, the application is limited to projects funded by governments or nonprofit organizations and foundations. Privately funded research should be gauged according to its private returns, such as the net operating profit after tax. Still, our approach is an appropriate tool to assess various types of research, like academic or industrial research, basic or applied research, curiosity-driven or mission-oriented research, development, and past or present projects.

Tax payments present convenient inputs for benefit-cost analyses and calculations of the net present value (NPV) or the internal rate of return (IRR). The latter two metrics stemming originally from corporate finance allow for comparisons with returns on corporate R\&D investments and, because of their widespread use in industry, potentially foster the understanding by business professionals for such studies (Tassey 2003).

Our approach has several advantages justifying its application in addition to the established methods. It assesses a direct benefit to countries funding research, which has been largely neglected by existing studies. The consideration of fiscal income is intuitive, as it is clear that these funds can be used to finance new research or to support other areas of expenditure. For instance, it is possible to determine how many research projects could be funded with the returns on only one single successful program. Furthermore, our approach can be executed on different levels of complexity, such as with or without substitution effects or taxes arising from secondary impacts, depending on the goal of a study and on the available resources. For instance, it can be limited to an in-depth analysis of a welldefined case considering a small number of directly involved scientists and companies, as in the case of saccharin presented hereafter. Alternatively, it is possible to apply it to a larger number of research groups and entire industries including their indirect and induced impacts, if appropriate multipliers are available, e.g. for the biotechnology industry (Ernst and Young 2000). Depending on the case and the goal of a study, short- or long-term impacts of the involved research projects can be considered.

Recently Linquiti (2012) suggested including risk in the ex-post valuation of $R \& D$. His reasoning can be considered in studies using our approach as well, but it should be noted that the author excluded basic research, as it entails great uncertainties, which cannot be easily quantified.

Our method can draw on different data sources, which have to be selected according to their availability. In a historic example like saccharin, the use of archival material, such as annual reports, meeting minutes, and industry publications, might be necessary to complement publicly available data making a study more laborious. In other cases, for instance, regarding the biotechnology industry, published documents should be sufficient to 
retrieve the relevant numbers. For very recent examples and forward projecting studies, it is even conceivable to obtain data from involved companies directly.

Finally, a further advantage of our method is the consideration of actual cash flows, which involves fewer assumptions compared with, e.g. econometric tools.

Of course, it should be remarked that the preparation of evaluation case studies using our approach entails the same issues inherent to case studies in general (Salter and Martin 2001; Martin and Tang 2006): performing case studies is time-consuming, and their results are difficult to generalize. Further, the focus on a few research projects leading to the desired detailed understanding might concomitantly limit the view for the big picture. Case studies have also been critiqued because they tend to consider successful projects only. However, Scherer and Harhoff (2000) argue that in a portfolio of research projects, there are always just a few successful ones, which may or may not cover the expenses of the remaining projects.

In the following section, we use the discovery and commercialization of saccharin to demonstrate the application of our approach.

\section{Example of application: saccharin}

As mentioned before, we chose to demonstrate our approach with saccharin as a well-defined example, limiting our focus on Remsen's research group at The Johns Hopkins University and on Monsanto's commercial production of the sweetener. Hereafter we assess the public returns on the investment in Remsen's curiosity-driven fundamental research project, ignoring Fahlberg's private development costs and all private rates of return. ${ }^{1}$ Data regarding the research expenses of the Remsen group were found in the Special Collections of The Johns Hopkins University in Baltimore, MD. Figures related to the commercialization of saccharin were retrieved from Monsanto's company records held by the Archives of the Washington University in St. Louis, MO, and additionally from government publications available through the Internet or at the National Archives in College Park, MD.

We start by presenting the calculations of the tax payments accruing from Monsanto's saccharin operations, as this is the core of our approach. This is challenging for the evaluator, as the company of course did not break its tax payments down into the shares of individual products. One of our main tasks was, therefore, to find appropriate assumptions to estimate saccharin's share in the total taxes paid by Monsanto during the 72 years of saccharin production. In the following, the rationales for the calculations in the individual years are presented. Years having similar or identical rationales were consolidated in respective tables. The history of saccharin as Monsanto's first product has been discussed elsewhere (Forster and Seeger in preparation b) and is only repeated below as far as necessary for understanding. Table 1 summarizes historical milestones.

The St. Louis businessman John F. Queeny founded his company Monsanto in 1901 specifically for the manufacturing of saccharin. Operations commenced on 6 March 1902. For the early years up to 1924, no annual accounts of the taxes paid by Monsanto were found in the company records. Therefore, the approximate tax burden is calculated using the appropriate tax rates, which are detailed in online Appendix A. Several publications served as sources to obtain the tax rates (Chirelstein et al. 1963; Hill 1913; Pyle 1922; Seligman 1970; Spaulding 1927; Tax Foundation 2012; United States Bureau of the Census 1915). Starting in 1924 the annual provisions for income taxes are available from Monsanto's annual reports. ${ }^{2}$ These values are used for the calculation of the fiscal income generated by saccharin from 1924 until its production by Monsanto ceased in 1972.

The estimation of the annual share of saccharin in Monsanto's total tax payments is tedious and has to be adapted according to the data available for the respective years. Whenever possible, the saccharin turnover as a percentage of total sales was calculated as a proxy for its share in taxes. The capital bound for the production of saccharin, which would be needed for an exact calculation of the property tax, or the profitability of the saccharin operations, required for a precise determination of the income tax, are unknown for almost the entire time span. With exception of the years 1901 to 1903, during which the share is unambiguous because there was only one product, three scenarios were developed for saccharin's share in taxation for each year. The base (medium) scenario calculated with the sales proxy mentioned above implies that the profitability of the saccharin operations represents exactly the average profitability of all Monsanto products - an assumption, which cannot be applied to the entire time series, as described below. Beginning with the medium scenario, a high $(+50 \%)$ and a low scenario $(-50 \%)$ were developed. Based on all the available information for the respective years contained in annual reports, government publications, internal documents, etc., one of these three scenarios was chosen as the realistic one. A detailed example for 1 year with comments on every calculation step is provided in online Appendix B. Additional comments on the year by year calculations, which are not essential for the main argument, can be found in online Appendix C.

The total fiscal income generated by Monsanto's saccharin operations is provided in four different ways: the mentioned high $(\mathrm{H})$, medium $(\mathrm{M})$, and low $(\mathrm{L})$ scenarios, and the realistic scenario, which represents the sum of all values considered realistic in the individual years. For clarity reasons, only the realistic scenario is shown in each of the tables below, which indicate the scenario $(\mathrm{H} / \mathrm{M} / \mathrm{L})$ selected as the realistic one. 
Table 1. Key events in the history of Monsanto related to saccharin

\begin{tabular}{ll}
\hline Year & Event \\
\hline 1878 & Discovery of saccharin by Fahlberg supervised by Remsen at The Johns Hopkins University \\
1887 & Market introduction of saccharin in Germany by Fahlberg, List \& Co. \\
1901 & Formation of Monsanto Chemical Works in St. Louis specifically for the production of saccharin \\
1902 & Production of saccharin Monsanto commenced \\
& Start of price war by incumbent German companies \\
1903 & First exports of saccharin Monsanto \\
1904 & Expansion of Monsanto's product portfolio \\
1905 & Monsanto's first profitable year \\
$1912-59$ & Implementation of Food Inspection Decision (FID) 135/142 curtailing US saccharin market \\
$1914-8$ & Sugar shortage during World War I leading to high saccharin demand and prices \\
1920 & Largest producer of saccharin in the World because of competitors' problems in World War I \\
1925 & Legal proceedings against Monsanto violating FID 142 ended after hung jury \\
& No domestic competitor in the saccharin market left \\
$1941-5$ & Sugar shortage during World War II leading to high saccharin demand \\
1950 & Introduction of cyclamate sweeteners by Abbott \\
1952 & Market entry of Maumee Chemical Company using an alternative synthesis process for saccharin \\
$1963-5$ & Repeated considerable expansion of capacity to satisfy demand \\
$1964-$ & Pricing pressure due to domestic and foreign competition \\
1972 & Management decision to shut down Monsanto's saccharin production \\
\hline
\end{tabular}

Source: Forster and Seeger (in preparation b).

Table 2. Calculations of taxes attributable to Monsanto's saccharin operations (1901-8)

\begin{tabular}{|c|c|c|c|c|c|c|c|c|}
\hline Year & Scenario & Total sales $[\$]$ & $\begin{array}{l}\text { Saccharin } \\
\text { sales [\$] }\end{array}$ & $\begin{array}{l}\text { Saccharin } \\
\text { sales [\%] }\end{array}$ & Total assets $[\$]$ & Tax rate $[\%]$ & Total tax $[\$]$ & $\begin{array}{l}\text { Saccharin } \\
\text { tax }[\$]\end{array}$ \\
\hline 1901 & $\mathrm{~N}$ & 0 & 0 & 0 & 5000 & $0.55^{\mathrm{a}}$ & $28^{\mathrm{a}}$ & $28^{\mathrm{a}}$ \\
\hline 1902 & $\mathrm{~N}$ & 21,870 & 21,870 & 100 & 18,500 & $0.55^{\mathrm{a}}$ & $102^{\mathrm{a}}$ & $102^{\mathrm{a}}$ \\
\hline 1903 & $\mathrm{~N}$ & 39,275 & 39,275 & 100 & 27,200 & $0.55^{\mathrm{a}}$ & $150^{\mathrm{a}}$ & $150^{\mathrm{a}}$ \\
\hline 1904 & $\mathrm{~N}$ & $\mathrm{n} / \mathrm{d}$ & 36,456 & $\mathrm{n} / \mathrm{a}$ & 35,100 & $0.55^{\mathrm{a}}$ & $193^{\mathrm{a}}$ & $164^{\mathrm{a}}$ \\
\hline 1905 & M & 112,000 & 33,338 & $30^{\mathrm{a}}$ & 46,600 & $0.55^{\mathrm{a}}$ & $256^{\mathrm{a}}$ & $115^{\mathrm{a}}$ \\
\hline 1906 & M & 120,000 & 33,005 & $28^{\mathrm{a}}$ & 76,900 & $0.55^{\mathrm{a}}$ & $423^{\mathrm{a}}$ & $118^{\mathrm{a}}$ \\
\hline 1907 & M & 151,300 & 29,856 & $20^{\mathrm{a}}$ & 96,900 & $0.55^{\mathrm{a}}$ & $533^{\mathrm{a}}$ & $107^{\mathrm{a}}$ \\
\hline 1908 & M & 168,200 & $\mathrm{n} / \mathrm{d}$ & $\mathrm{n} / \mathrm{a}$ & 117,300 & $0.55^{\mathrm{a}}$ & $645^{\mathrm{a}}$ & $129^{\mathrm{a}}$ \\
\hline
\end{tabular}

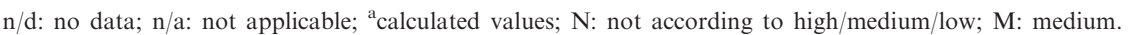

Sources: see text.

As saccharin was Monsanto's first and-until the introduction of caffeine in 1904 - only product, all taxes paid in the years 1901 through 1903 and a large part of 1904's taxes (as in the medium scenario) are attributable to saccharin (Table 2). ${ }^{3}$ Although Monsanto's operations yielded a loss in each of these 4 years, the tax was due on property, and it is therefore assumed that it had to be paid anyway. From 1905 to 1907 Monsanto introduced several new products, such as vanillin, iron, bismuth, thymol, and phenacetin, ${ }^{4}$ most likely associated with a reduction of saccharin's share in bound capital and thus taxes. In 1905 we begin to apply our high/medium/low scenario framework, explaining the tax fluctuation from 1904 to 1905 .

According to notes from Jules Bebie's diary-Bebie was one of three skilled Swiss chemists working for Queeny
(Forster and Seeger in preparation b) - Monsanto made $\$ 8,000$ profits on saccharin sales in 1910 . This corresponds to $10.53 \%$ of all profits if products with negative returns are not considered (Table 3). ${ }^{5}$ The percentage can directly be applied to calculate the share in income taxation, as there is no need to produce three scenarios from a profit figure. The income tax in 1909 is calculated retrospectively with the same value. The share in property taxation is estimated to be the same as in the previous years, as no new products were introduced (Forrestal 1977: 260). A notable increase in assets from 1909 to 1910 explains the higher tax payments in 1910 .

In the leaflet 'Information regarding Monsanto for purchasers of Mortgage', issued in 1920, the only kind of taxes mentioned for the years 1915 through 1919 are federal taxes (Table 4). ${ }^{6}$ The reason possibly is that property 
Table 3. Calculations of taxes attributable to Monsanto's saccharin operations (1909-14)

\begin{tabular}{|c|c|c|c|c|c|c|c|c|c|c|c|c|}
\hline Year & $\begin{array}{l}\text { Scenario } \\
\text { [property, } \\
\text { income] }\end{array}$ & $\begin{array}{l}\text { Total } \\
\text { sales } \\
{[\$]}\end{array}$ & $\begin{array}{l}\text { Saccharin } \\
\text { sales } \\
{[\$]}\end{array}$ & $\begin{array}{l}\text { Total } \\
\text { income } \\
{[\$]}\end{array}$ & $\begin{array}{l}\text { Income } \\
\text { tax rate } \\
{[\%]}\end{array}$ & $\begin{array}{l}\text { Saccharin } \\
\text { income tax } \\
{[\%]}\end{array}$ & $\begin{array}{l}\text { Saccharin } \\
\text { income tax } \\
{[\$]}\end{array}$ & $\begin{array}{l}\text { Total } \\
\text { assets } \\
{[\$]}\end{array}$ & $\begin{array}{l}\text { Property } \\
\text { tax rate } \\
{[\%]}\end{array}$ & $\begin{array}{l}\text { Saccharin } \\
\text { property tax } \\
{[\%]}\end{array}$ & $\begin{array}{l}\text { Saccharin } \\
\text { property tax } \\
{[\$]}\end{array}$ & $\begin{array}{l}\text { Saccharin } \\
\text { total tax } \\
{[\$]}\end{array}$ \\
\hline 1909 & $\mathrm{M}, \mathrm{M}$ & 232,900 & $\mathrm{n} / \mathrm{d}$ & 15,800 & 1 & 10 & $11^{\mathrm{a}}$ & 154,200 & 0.55 & 20 & $170^{\mathrm{a}}$ & $181^{\mathrm{a}}$ \\
\hline 1910 & $\mathrm{M}, \mathrm{N}$ & 358,000 & $\mathrm{n} / \mathrm{d}$ & 29,300 & 1 & $10.53^{\mathrm{a}}$ & $26^{\mathrm{a}}$ & 267,300 & 0.55 & 20 & $294^{\mathrm{a}}$ & $320^{\mathrm{a}}$ \\
\hline 1911 & $\mathrm{M}, \mathrm{M}$ & 401,000 & $\mathrm{n} / \mathrm{d}$ & 66,900 & 1 & 10 & $63^{\mathrm{a}}$ & 292,200 & 0.55 & 20 & $321^{\mathrm{a}}$ & $384^{\mathrm{a}}$ \\
\hline 1912 & $\mathrm{M}, \mathrm{M}$ & 462,000 & $\mathrm{n} / \mathrm{d}$ & 80,700 & 1 & 9 & $69^{\mathrm{a}}$ & 388,700 & 0.55 & 18 & $385^{\mathrm{a}}$ & $454^{\mathrm{a}}$ \\
\hline 1913 & $\mathrm{M}, \mathrm{M}$ & 517,000 & 50,000 & 81,500 & 1 & $9^{\mathrm{a}}$ & $74^{\mathrm{a}}$ & 437,800 & 0.55 & 18 & $433^{\mathrm{a}}$ & $508^{\mathrm{a}}$ \\
\hline 1914 & $\mathrm{M}, \mathrm{M}$ & 684,000 & 95,000 & 150,200 & 1 & $14^{\mathrm{a}}$ & $212^{\mathrm{a}}$ & 490,400 & 0.55 & 15 & $405^{\mathrm{a}}$ & $617^{\mathrm{a}}$ \\
\hline
\end{tabular}

n/d: no data; estimated values; ${ }^{a}$ calculated values; N: not according to high/medium/low; M: medium.

Sources: see text.

Table 4. Calculations of taxes attributable to Monsanto's saccharin operations (1915-9)

\begin{tabular}{|c|c|c|c|c|c|c|c|c|}
\hline 1915 & M & 1,240 & 171 & $14^{\mathrm{a}}$ & 561 & 1 & $14^{\mathrm{a}}$ & $793^{\mathrm{a}}$ \\
\hline 1916 & M & 2,929 & 720 & $25^{\mathrm{a}}$ & 905 & 2 & $25^{\mathrm{a}}$ & $4616^{\mathrm{a}}$ \\
\hline 1917 & $\mathrm{H}$ & 4,297 & 1,475 & $34^{\mathrm{a}}$ & 775 & 29 & $52^{\mathrm{a}}$ & $163,772^{\mathrm{a}}$ \\
\hline
\end{tabular}

acalculated values; M: medium; H: high.

Sources: see text.

taxes were small compared with income taxes during those years, as profits in excess of prewar earnings were charged heavily, which increased Monsanto's income tax burdens disproportionately. Consequentially, property taxation is no longer considered for the calculations of the remaining years until 1924, when the total taxes paid by Monsanto become available from its annual reports anyway. As the federal taxes in the leaflet are only provided in the form of a sum over 1915 through $1919(\$ 2,164,850)$, the income tax paid in each individual year is still calculated using the income tax rates (including excess profits tax) and saccharin's share in total sales. ${ }^{7}$

The considerable increase in tax payments accruing from the saccharin operations from 1915 to 1917 can be explained by several influencing factors: firstly, incomes were markedly heavier taxed during the War; secondly, sales reached new records every year; thirdly, the scenario was changed from medium to high from 1916 to 1917 . The subsequent decrease in 1918 and 1919 is due to lower relative profits and saccharin's lower share in those profits.

The period between 1919 and 1942 lacks information about the value or amount of Monsanto's saccharin sales. Data about the sales of saccharin and-laterflavors in general, provided by the United States Tariff Commission's reports on synthetic organic chemicals, ${ }^{8}$ served as an estimation basis for these years, but these estimations are of course marred by uncertainty. In 1920 the total production of the saccharin industry plummeted to $25 \%$ of the 1919 figure because sugar became more readily available again after the war. ${ }^{9}$ This translates together with markedly reduced tax rates into the large difference between the tax payments of the 2 years.

As Monsanto was the largest of five saccharin producers in the USA after the War and, until 1925, squeezed every one of its rivals out of the market (Forster and Seeger in preparation b), it is assumed that the company's share of the total market was $80 \%$ already in 1920 . Furthermore, this also implies to use the medium scenarios for the calculation of saccharin's tax burden during those years. Regarding Table 5, the tenfold increase of tax payments from 1922 to 1923 resulted from significantly better total net incomes.

As there were only two producers left in the market in 1924, the United States Tariff Commission omitted the detailed reporting of saccharin production and sales figures for competitive reasons. Therefore, these numbers had to be estimated for the year 1924 and all subsequent years until 1942 using the production and sales figures of the entire flavor category. Furthermore, saccharin market prices are unknown for the years 1925 through 
Table 5. Calculations of taxes attributable to Monsanto's saccharin operations (1920-3)

\begin{tabular}{|c|c|c|c|c|c|c|c|c|}
\hline Year & Scenario & $\begin{array}{l}\text { Saccharin } \\
\text { sales total } \\
{[\$, 000]}\end{array}$ & $\begin{array}{l}\text { Monsanto } \\
\text { share [\%] }\end{array}$ & $\begin{array}{l}\text { Saccharin } \\
\text { sales of } \\
\text { total }[\%]\end{array}$ & $\begin{array}{l}\text { Total income } \\
{[\$, 000]}\end{array}$ & $\begin{array}{l}\text { Income tax } \\
\text { rate }[\%]\end{array}$ & $\begin{array}{l}\text { Saccharin } \\
\text { income } \\
\operatorname{tax}[\%]\end{array}$ & $\begin{array}{l}\text { Saccharin } \\
\text { income } \\
\operatorname{tax}[\$]\end{array}$ \\
\hline 1920 & M & 419 & 80 & $4^{\mathrm{a}}$ & 772 & 11.5 & $4^{\mathrm{a}}$ & $4,000^{\mathrm{a}}$ \\
\hline 1921 & M & 522 & 85 & $12^{\mathrm{a}}$ & (132) & 11.5 & $12^{\mathrm{a}}$ & $9,240^{\mathrm{a}, \mathrm{b}}$ \\
\hline 1922 & $\mathrm{M}$ & 630 & 80 & $14^{\mathrm{a}}$ & 53 & 13.5 & $13.5^{\mathrm{a}}$ & $1,064^{\mathrm{a}}$ \\
\hline 1923 & M & 662 & 90 & $15^{\mathrm{a}}$ & 447 & 13.5 & $15^{\mathrm{a}}$ & $10,420^{\mathrm{a}}$ \\
\hline
\end{tabular}

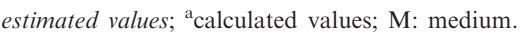

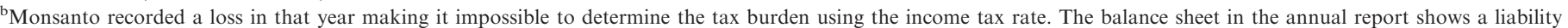

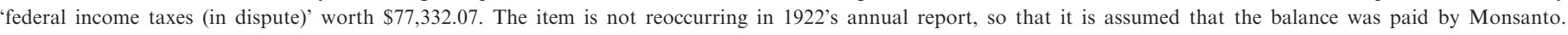
Saccharin's share in taxation of 1921 is therefore calculated on this basis.

Sources: see text.

Table 6. Calculations of taxes attributable to Monsanto's saccharin operations (1924-35)

\begin{tabular}{|c|c|c|c|c|c|c|c|c|}
\hline Year & Scenario & $\begin{array}{l}\text { Total flavor } \\
\text { sales }[\$, 000]\end{array}$ & $\begin{array}{l}\text { Max. possible } \\
\text { saccharin } \\
\text { sales }[\$, 000]\end{array}$ & $\begin{array}{l}\text { Monsanto } \\
\text { saccharin } \\
\text { sales }[\$, 000]\end{array}$ & $\begin{array}{l}\text { Monsanto } \\
\text { total sales } \\
{[\$, 000]}\end{array}$ & $\begin{array}{l}\text { Saccharin } \\
\text { income } \\
\operatorname{tax}[\%]\end{array}$ & $\begin{array}{l}\text { Total income } \\
\text { tax }[\$, 000]\end{array}$ & $\begin{array}{l}\text { Saccharin } \\
\text { income tax [\$] }\end{array}$ \\
\hline 1924 & M & 1,471 & 574 & $563^{\mathrm{a}}$ & 4,045 & $14^{\mathrm{a}}$ & 30 & $4,200^{\mathrm{a}}$ \\
\hline 1925 & M & 1,409 & 402 & $387^{\mathrm{a}}$ & 4,822 & $8^{\mathrm{a}}$ & 31 & $2,480^{\mathrm{a}}$ \\
\hline 1926 & M & 1,483 & 386 & $379^{\mathrm{a}}$ & 5,090 & $7.5^{\mathrm{a}}$ & 62 & $4,650^{\mathrm{a}}$ \\
\hline 1927 & M & 1,435 & 438 & $362^{\mathrm{a}}$ & 5,553 & $6.5^{\mathrm{a}}$ & 82 & $5,330^{\mathrm{a}}$ \\
\hline 1928 & $\mathrm{M}$ & 1,296 & 408 & $368^{\mathrm{a}}$ & 6,149 & $6^{\mathrm{a}}$ & 170 & $10,200^{\mathrm{a}}$ \\
\hline 1929 & M & 3,517 & 440 & $379^{\mathrm{a}}$ & 17,088 & $2^{\mathrm{a}}$ & 230 & $4,600^{\mathrm{a}}$ \\
\hline 1930 & M & 2,739 & 356 & $324^{\mathrm{a}}$ & 13,487 & $2.25^{\mathrm{a}}$ & 105 & $2,363^{\mathrm{a}}$ \\
\hline 1931 & M & $\mathrm{n} / \mathrm{d}$ & $\mathrm{n} / \mathrm{d}$ & $\mathrm{n} / \mathrm{d}$ & 13,126 & 2 & 172 & $3,440^{\mathrm{a}}$ \\
\hline 1932 & M & $\mathrm{n} / \mathrm{d}$ & $\mathrm{n} / \mathrm{d}$ & $\mathrm{n} / \mathrm{d}$ & 11,408 & 2 & 232 & $4,640^{\mathrm{a}}$ \\
\hline 1933 & M & 1,797 & 368 & $312^{\mathrm{a}}$ & 15,497 & $2^{\mathrm{a}}$ & 422 & $8,440^{\mathrm{a}}$ \\
\hline 1934 & M & 1,929 & 386 & $254^{\mathrm{a}}$ & 17,544 & $1.5^{\mathrm{a}}$ & 482 & $7,230^{\mathrm{a}}$ \\
\hline 1935 & M & 2,095 & 492 & $332^{\mathrm{a}}$ & 24,706 & $1.25^{\mathrm{a}}$ & 645 & $8,063^{\mathrm{a}}$ \\
\hline
\end{tabular}

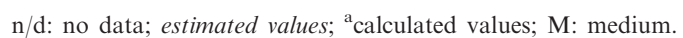

Sources: see text.

1938. For the interpolation, it was assumed that the prices steadily fell from their 1925 level to 1938 's level. ${ }^{10}$ Concomitantly, the ratio of the price of toluene-an important precursor in Monsanto's saccharin synthesis-in respect of the saccharin price increased from 0.19 in 1925 to 0.23 in 1938 curtailing the margin. As it is probable that Monsanto was able to capitalize on learning effects in its saccharin production, it is nevertheless assumed that the medium scenario for saccharin's share in taxation is realistic.

In 1922 saccharin sales made up $50 \%$ of the dollar value of all flavor category sales, but as new products were introduced, this ratio dropped. For instance, in 1924, all products, for which detailed figures could not be published, accounted for $39 \%$ of the total flavor sales value and for only for $19 \%$ of the sales volume. It is obvious that saccharin is bound to those two limits, but considering its sales volume and value in the early 1920s, it seems that it must represent the bulk of these residual numbers. ${ }^{11}$ As mentioned before, starting in 1924, Monsanto's total income tax payments became available from its annual reports explaining the difference between 1923 and 1924 . The fluctuations of the values in Table 6 themselves are mainly caused by the indirect calculation based on the total flavor category sales, as introduced above, which depend on the faithful reporting of the involved companies. Further influences include a marked increase in Monsanto's total income taxes from 1927 to 1928 and a considerable decrease from 1929 to 1930 as well as the acquisition of Merrimac Chemical Company in 1929 resulting in higher group sales (Forrestal 1977: 74).

In 1936 the structure of the United States Tariff Commission's publication 'Dyes and Other Synthetic Organic Chemicals in the United States' was revised (Table 7). From then on, flavors and perfume materials were reported as one group, while concomitantly 
Table 7. Calculations of taxes attributable to Monsanto's saccharin operations (1935-41)

\begin{tabular}{|c|c|c|c|c|c|c|c|c|}
\hline Year & Scenario & $\begin{array}{l}\text { Saccharin } \\
\text { production } \\
{[, 000 \mathrm{lb} .]}\end{array}$ & $\begin{array}{l}\text { Saccharin } \\
\text { price }[\$ / \text { lb.] }\end{array}$ & $\begin{array}{l}\text { Monsanto } \\
\text { saccharin } \\
\text { sales }[\$, 000]\end{array}$ & $\begin{array}{l}\text { Monsanto } \\
\text { total sales } \\
{[\$, 000]}\end{array}$ & $\begin{array}{l}\text { Saccharin } \\
\text { income tax [\%] }\end{array}$ & $\begin{array}{l}\text { Total income } \\
\operatorname{tax}[\$, 000]\end{array}$ & $\begin{array}{l}\text { Saccharin } \\
\text { income tax }[\$]\end{array}$ \\
\hline 1935 & M & 255 & 1.3 & $332^{\mathrm{a}}$ & 24,706 & $1.25^{\mathrm{a}}$ & 645 & $8,063^{\mathrm{a}}$ \\
\hline 1936 & M & 260 & 1.2 & $312^{\mathrm{a}}$ & 28,848 & $1^{\mathrm{a}}$ & 1,029 & $10,290^{\mathrm{a}}$ \\
\hline 1937 & M & 265 & 1.1 & $292^{\mathrm{a}}$ & 33,202 & $0.75^{\mathrm{a}}$ & 1,030 & $7,725^{\mathrm{a}}$ \\
\hline 1938 & M & 270 & 1.0 & $266^{\mathrm{a}}$ & 31,935 & $0.75^{\mathrm{a}}$ & 854 & $6,405^{\mathrm{a}}$ \\
\hline 1941 & $\mathrm{H}$ & 500 & 1.3 & $601^{\mathrm{a}}$ & 63,756 & $1.5^{\mathrm{a}}$ & 9,609 & $144,135^{\mathrm{a}}$ \\
\hline
\end{tabular}

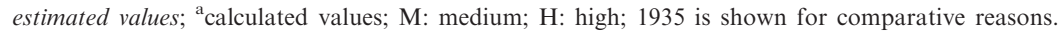

Sources: see text.

Table 8. Calculations of taxes attributable to Monsanto's saccharin operations (1942-50)

\begin{tabular}{|c|c|c|c|c|c|c|c|c|}
\hline Year & Scenario & $\begin{array}{l}\text { Saccharin } \\
\text { production } \\
{[, 000 \text { lb. }]}\end{array}$ & $\begin{array}{l}\text { Saccharin } \\
\text { price }[\$ / 1 b .]\end{array}$ & $\begin{array}{l}\text { Monsanto } \\
\text { saccharin } \\
\text { sales }[\$, 000]\end{array}$ & $\begin{array}{l}\text { Monsanto } \\
\text { total sales } \\
{[\$, 000]}\end{array}$ & $\begin{array}{l}\text { Saccharin } \\
\text { income tax [\%] }\end{array}$ & $\begin{array}{l}\text { Total income } \\
\text { tax }[\$, 000]\end{array}$ & $\begin{array}{l}\text { Saccharin } \\
\text { income tax }[\$]\end{array}$ \\
\hline 1942 & $\mathrm{H}$ & $1,073^{\mathrm{a}}$ & 1.3 & 1,393 & 69,147 & $3^{\mathrm{a}}$ & 11,001 & $330,030^{\mathrm{a}}$ \\
\hline 1943 & $\mathrm{H}$ & $1,217^{\mathrm{a}}$ & 1.1 & 1,393 & 81,697 & $2.63^{\mathrm{a}}$ & 10,085 & $264,731^{\mathrm{a}}$ \\
\hline 1944 & $\mathrm{H}$ & 1,400 & 1.1 & $1,540^{\mathrm{a}}$ & 86,996 & $2.63^{\mathrm{a}}$ & 10,033 & $263,366^{\mathrm{a}}$ \\
\hline 1945 & $\mathrm{H}$ & 1,400 & 1.1 & $1,540^{\mathrm{a}}$ & 95,339 & $2.25^{\mathrm{a}}$ & 9,856 & $221,760^{\mathrm{a}}$ \\
\hline 1948 & $\mathrm{M}$ & 1,200 & 1.2 & $1,464^{\mathrm{a}}$ & 161,609 & $1^{\mathrm{a}}$ & 10,129 & $101,290^{\mathrm{a}}$ \\
\hline 1949 & M & 1,200 & 1.3 & $1,560^{\mathrm{a}}$ & 165,925 & $1^{\mathrm{a}}$ & 10,823 & $108,230^{\mathrm{a}}$ \\
\hline 1950 & M & 1,207 & $1.4^{\mathrm{a}}$ & 1,679 & 227,135 & $0.75^{\mathrm{a}}$ & 27,789 & $208,418^{\mathrm{a}}$ \\
\hline
\end{tabular}

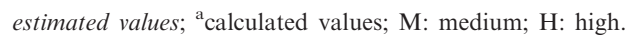

Sources: see text.

discriminating between substances of coal-tar and noncoal-tar origin. Consequently, the number of products in saccharin's category increased significantly, rendering comparisons less meaningful. Therefore, it was simply assumed that the sales volume of saccharin increased slightly but steadily until the beginning of World War II, when the demand increased sharply due to shortages in sugar supply (United States Tariff Commission 1946). The prices for 1938-41 were extracted from an official document prepared by Monsanto. ${ }^{12}$

Saccharin sales values and prices for the years 1942 and 1943 are known from Monsanto documents, which allow a more precise estimation of saccharin's share in taxation for these 2 years (Table 8). ${ }^{13}$ According to the United States Tariff Commission, high production levels still prevailed in 1944 and 1945. For the years 1946 through 1949 it was assumed that saccharin production volumes and prices steadily moved to their level of 1950 , for which internal Monsanto figures were found. ${ }^{14}$

No data about Monsanto's saccharin production are available until 1958 (Table 9). In the early 1950s Abbott introduced its cyclamate sweeteners to the market. However, in the beginning, cyclamates were no real threat to saccharin due to their higher price. ${ }^{15}$ It was even suggested that the introduction might have been beneficial for saccharin because many states were reconsidering their strict regulations toward saccharin and because combination products of saccharin and cyclamates were sold. ${ }^{16}$ It is thus assumed that Monsanto's output stayed flat and eventually slightly declined as the Maumee Chemical Company entered the field with a novel production process for saccharin in 1952. According to the US Department of Agriculture, prices were fairly constant. ${ }^{17}$ However, Monsanto felt compelled to reduce its prices in late 1959 to counter Japanese imports. ${ }^{18}$ Therefore, it seems appropriate to use the low scenarios for the calculation of the taxes attributable to saccharin from 1959 to 1962, when the demand and therefore capacity usage were increasing again.

The early sixties saw a rapid increase in consumption of noncaloric sweeteners, as people started to use noncaloric sweeteners to control their weight and to reduce sugar 
Table 9. Calculations of taxes attributable to Monsanto's saccharin operations (1951-9)

\begin{tabular}{|c|c|c|c|c|c|c|c|c|}
\hline Year & Scenario & $\begin{array}{l}\text { Saccharin } \\
\text { production } \\
{[, 00 \text { lb. }]}\end{array}$ & $\begin{array}{l}\text { Saccharin } \\
\text { price }[\$ / \mathrm{lb} .]\end{array}$ & $\begin{array}{l}\text { Monsanto } \\
\text { saccharin } \\
\text { sales }[\$, 000]\end{array}$ & $\begin{array}{l}\text { Monsanto } \\
\text { total sales }[\$, 000]\end{array}$ & $\begin{array}{l}\text { Saccharin income } \\
\operatorname{tax}[\%]\end{array}$ & $\begin{array}{l}\text { Total income } \\
\text { tax }[\$, 000]\end{array}$ & $\begin{array}{l}\text { Saccharin } \\
\text { income tax [\$] }\end{array}$ \\
\hline 1951 & M & $1,143^{\mathrm{a}}$ & 1.4 & 1,600 & 272,845 & $0.5^{\mathrm{a}}$ & 38,643 & $193,215^{\mathrm{a}}$ \\
\hline 1952 & $\mathrm{M}$ & $1,143^{\mathrm{a}}$ & 1.4 & 1,600 & 266,704 & $0.5^{\mathrm{a}}$ & 18,088 & $90,440^{\mathrm{a}}$ \\
\hline 1953 & $\mathrm{M}$ & $1,000^{\mathrm{a}}$ & 1.5 & 1,500 & 340,617 & $0.45^{\mathrm{a}}$ & 23,060 & $103,770^{\mathrm{a}}$ \\
\hline 1954 & $\mathrm{M}$ & $933^{\mathrm{a}}$ & 1.5 & 1,400 & 341,823 & $0.45^{\mathrm{a}}$ & 18,854 & $84,843^{\mathrm{a}}$ \\
\hline 1955 & $\mathrm{M}$ & $875^{\mathrm{a}}$ & 1.6 & 1,400 & 522,349 & $0.3^{\mathrm{a}}$ & 36,898 & $110,694^{\mathrm{a}}$ \\
\hline 1956 & $\mathrm{M}$ & $906^{\mathrm{a}}$ & 1.6 & 1,450 & 541,883 & $0.3^{\mathrm{a}}$ & 30,764 & $92,292^{\mathrm{a}}$ \\
\hline 1957 & $\mathrm{M}$ & $938^{\mathrm{a}}$ & 1.6 & 1,500 & 567,116 & $0.3^{\mathrm{a}}$ & 29,862 & $89,586^{\mathrm{a}}$ \\
\hline 1958 & $\mathrm{M}$ & $1,011^{\mathrm{a}}$ & 1.6 & 1,617 & 547,557 & $0.3^{\mathrm{a}}$ & 23,052 & $69,156^{\mathrm{a}}$ \\
\hline 1959 & $\mathrm{~L}$ & $1,000^{\mathrm{a}}$ & 1.6 & 1,600 & 616,377 & $0.13^{\mathrm{a}}$ & 36,796 & $45,995^{\mathrm{a}}$ \\
\hline
\end{tabular}

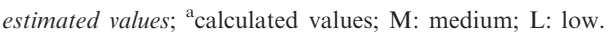

Sources: see text.

Table 10. Calculations of taxes attributable to Monsanto's saccharin operations (1960-72)

\begin{tabular}{|c|c|c|c|c|c|c|c|c|}
\hline Year & Scenario & $\begin{array}{l}\text { Saccharin } \\
\text { production } \\
{[, 000 \mathrm{lb} .]}\end{array}$ & $\begin{array}{l}\text { Saccharin } \\
\text { price }[\$ / \text { lb.] }\end{array}$ & $\begin{array}{l}\text { Monsanto } \\
\text { saccharin } \\
\text { sales }[\$, 000]\end{array}$ & $\begin{array}{l}\text { Monsanto } \\
\text { total sales } \\
{[\$, 000]}\end{array}$ & $\begin{array}{l}\text { Saccharin } \\
\text { income tax }[\%]\end{array}$ & $\begin{array}{l}\text { Total income } \\
\operatorname{tax}[\$, 000]\end{array}$ & $\begin{array}{l}\text { Saccharin } \\
\text { income tax [\$] }\end{array}$ \\
\hline 1960 & $\mathrm{~L}$ & 1,200 & 1.4 & $1,680^{\mathrm{a}}$ & 890,114 & $0.08^{\mathrm{a}}$ & 58,793 & $44,095^{\mathrm{a}}$ \\
\hline 1961 & $\mathrm{~L}$ & 1,200 & 1.5 & $1,776^{\mathrm{a}}$ & 932,916 & $0.08^{\mathrm{a}}$ & 58,384 & $43,788^{\mathrm{a}}$ \\
\hline 1962 & M & 1,150 & 1.6 & $1,794^{\mathrm{a}}$ & $1,063,195$ & $0.15^{\mathrm{a}}$ & 62,915 & $94,373^{\mathrm{a}}$ \\
\hline 1963 & M & 1,200 & 1.6 & $1,920^{\mathrm{a}}$ & $1,192,270$ & $0.15^{\mathrm{a}}$ & 77,416 & $116,124^{\mathrm{a}}$ \\
\hline 1964 & $\mathrm{M}$ & 1,600 & 1.5 & $2,432^{\mathrm{a}}$ & $1,358,678$ & $0.2^{\mathrm{a}}$ & 99,178 & $198,356^{\mathrm{a}}$ \\
\hline 1965 & $\mathrm{~L}$ & 1,800 & 1.4 & $2,520^{\mathrm{a}}$ & $1,468,147$ & $0.08^{\mathrm{a}}$ & 79,638 & $59,729^{\mathrm{a}}$ \\
\hline 1966 & $\mathrm{~L}$ & 1,900 & $1.4^{\mathrm{a}}$ & $2,682^{\mathrm{a}}$ & $1,611,881$ & $0.08^{\mathrm{a}}$ & 76,420 & $57,315^{\mathrm{a}}$ \\
\hline 1967 & $\mathrm{~L}$ & 2,100 & $1.3^{\mathrm{a}}$ & $2,795^{\mathrm{a}}$ & $1,632,357$ & $0.08^{\mathrm{a}}$ & 66,469 & $49,852^{\mathrm{a}}$ \\
\hline 1968 & $\mathrm{~L}$ & 2,100 & $1.4^{\mathrm{a}}$ & $2,862^{\mathrm{a}}$ & $1,792,938$ & $0.08^{\mathrm{a}}$ & 82,107 & $61,580^{\mathrm{a}}$ \\
\hline 1969 & $\mathrm{~L}$ & 2,500 & $1.3^{\mathrm{a}}$ & $3,295^{\mathrm{a}}$ & $1,938,838$ & $0.08^{\mathrm{a}}$ & 73,473 & $55,105^{\mathrm{a}}$ \\
\hline 1970 & $\mathrm{~L}$ & $2,708^{\mathrm{a}}$ & $1.5^{\mathrm{a}}$ & $3,943^{\mathrm{a}}$ & $1,971,632$ & $0.1^{\mathrm{a}}$ & 35,017 & $35,017^{\mathrm{a}}$ \\
\hline 1971 & $\mathrm{~L}$ & 2,200 & 1.4 & $3,080^{\mathrm{a}}$ & $2,087,100$ & $0.05^{\mathrm{a}}$ & 65,700 & $32,850^{\mathrm{a}}$ \\
\hline 1972 & $\mathrm{~L}$ & 1,800 & 1.4 & $2,520^{\mathrm{a}}$ & $2,225,400$ & $0.05^{\mathrm{a}}$ & 80,600 & $40,300^{\mathrm{a}}$ \\
\hline
\end{tabular}

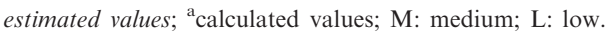

Sources: see text.

intake, even if not medically necessary (Table 10). ${ }^{19}$ The increased demand led Monsanto to expand its saccharin production capacity by $50 \%$ to about 1.8 million pounds annually by 1963 and again in 1965 to more than 3 million pounds annually. ${ }^{20}$ Saccharin's share in Monsanto's total sales was now only in the range of $0.1-0.2 \% .{ }^{21}$ Despite the favorable position in the market, we used the low scenarios for the calculations of saccharin's share in taxation starting in 1965 until Monsanto's exit of the saccharin market in 1972 , as the company had to lower the prices again to counter imports in 1964 and deplored pricing pressure in the saccharin market in its 1969 annual report in spite of record sales. ${ }^{22}$ Finally, in 1972, Monsanto stopped production of saccharin because of poor performance due to the competition of Sherwin-Williams and Japanese imports. At this point, we cease the estimation of saccharin tax data.
The tax payments presented in the tables above seem to be quite substantial. To make a meaningful assertion as to whether these values are still significant when compared with the research expenses, they have to be converted into a form that allows such comparisons. The question was approached in two different ways: on the one hand, we discounted all the fiscal incomes to the year 1876-as a preparation for the calculation of the benefit to cost ratio-and on the other hand, we considered the incomes in individual years indexed with the consumer price index.

For the calculations, we used annual figures of longterm US government bonds as discount rates. These are also officially applied by the Office of Management and Budget to estimate the returns on government investment projects (Tassey 2003). The sum of all the discounted tax payments is considerable in each of the four scenarios, as can be inferred from Table 11. ${ }^{23}$ 
Table 11. Sum of tax payments in the four scenarios discounted using yields of long-term US government bonds

\begin{tabular}{lrrrr}
\hline Scenario & Realistic & High & Medium & \multicolumn{1}{l}{ Low } \\
\hline Value in 1876 & $\$ 419,152$ & $\$ 576,579$ & $\$ 384,447$ & $\$ 192,306$ \\
${\text { Indexed to } 2011^{\text {a }}}$ & $\$ 9,070,000$ & $\$ 12,500,000$ & $\$ 8,320,000$ & $\$ 4,160,000$ \\
\hline
\end{tabular}

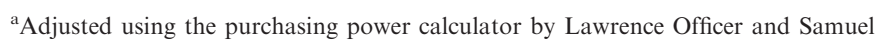
H. Williamson, MeasuringWorth, www.measuringworth.com (last access 10 June 2013), 2011.

The correspondence between Remsen and Gilman - the first President of The Johns Hopkins University-reveals information about the funds available to Remsen for his research projects when he acceded to his post. The relevant letters of the two men have been discussed in detail elsewhere (Forster and Seeger in preparation a). Using the values provided in the letters and with some additional estimation, it is possible to calculate the expenses of Remsen's research group in the years around the saccharin discovery. To render the calculations more realistic, we assume that saccharin was discovered in the context of a research project lasting 5 years, and we estimate the costs accordingly, although the discovery already happened during the second project year. In the beginning when Remsen came to The Johns Hopkins University, \$5,000 was invested for chemicals and apparatus and further $\$ 1,000$ for scientific literature (ibid.). Remsen's salary was distributed over the 5 years as follows: $\$ 3,000$ in 1877 and $1878, \$ 3,500$ in 1879 and 1880 , and $\$ 4,000$ in 1881. Further assuming recurring cost of chemicals, consumables and the literature of $\$ 1,500$ per year from 1878 to 1881 , and a yearly increase in the number of assistants from one in 1877 to five in 1881, each at a salary of $\$ 1,000$, the expenses total $\$ 44,000$ or $\$ 38,107$ when discounted with the relevant rates (Table 12).

Comparing the expenses with the discounted tax revenues, the values imply that -in the realistic scenario-more than 10 research projects of a similar scale could be funded in 1876 with the income generated by saccharin as just one successfully commercialized outcome of such a project. The benefit to cost ratio is thus more than 10 to 1 , and the NPV in 1876 was $\$ 381,046$.

When using a constant interest rate over the entire duration (1876-1972), instead of choosing the interest rates of each individual year, and setting the difference of the discounted incomes and expenses to zero, the IRR is obtained. In this metric, a project is profitable as long as its IRR is greater than the cost of capital.

$$
0=\sum_{i=1901}^{1972} \frac{\text { Fiscal Income }_{i}}{(1+I R R)^{(i-1875)}}-\sum_{i=1876}^{1881} \frac{\text { Research Investment }_{i}}{(1+I R R)^{(i-1875)}}
$$

Table 12. Estimation of the annual expenses of Remsen's research group (1876-81)

\begin{tabular}{lllrr}
\hline Year & $\begin{array}{l}\text { Interest } \\
\text { rate [\%] }\end{array}$ & $\begin{array}{l}\text { Discount } \\
\text { factor }\end{array}$ & $\begin{array}{l}\text { Expenses } \\
{[\$]}\end{array}$ & \multicolumn{1}{l}{$\begin{array}{l}\text { Discounted } \\
{[\$]}\end{array}$} \\
\hline 1876 & 3.66 & 1.0366 & 6,000 & 5,788 \\
1877 & 3.81 & 1.0760 & 4,000 & 3,717 \\
1878 & 3.97 & 1.1187 & 6,500 & 5,810 \\
1879 & 3.96 & 1.1630 & 8,000 & 6,878 \\
1880 & 3.63 & 1.2052 & 9,000 & 7,467 \\
1881 & 3.13 & 1.2430 & 10,500 & 8,447 \\
Total expenses & & & 44,000 & 38,106 \\
Indexed to 2011 $^{\text {a }}$ & & & 953,000 & 825,000 \\
\hline
\end{tabular}

${ }^{a}$ Adjusted using the purchasing power calculator by Lawrence Officer and Samuel H. Williamson, MeasuringWorth, www.measuringworth.com (last access 10 June 2013), 2011.

Sources: Forster and Seeger (in preparation a).

Table 13. IRRs for the four scenarios

\begin{tabular}{lllll}
\hline Scenario & Realistic & High & Medium & Low \\
\hline IRR $_{1876}$ & $7.68 \%$ & $7.99 \%$ & $7.20 \%$ & $5.93 \%$ \\
\hline
\end{tabular}

Sources: see text.

Calculating the IRR for the four saccharin scenarios, we obtain the values in Table 13 .

Compared with the rates that would be expected for corporate projects, these values may seem small. Nevertheless, in the realistic, high, and medium scenarios, the values are more than twice as big as the average interest paid on long-term government bonds, which makes the venture profitable.

The second way we chose to approach the question is based on the consideration of individual years instead of discounting and aggregating the values as above. Thereby, the income in each individual year is compared with the research expenses of an average year of the research project. The meaning of this approach is different from the previous one, as it determines the number of years, in which the fiscal income generated from the saccharin operations cover the annualized research expenses for a similar project. Based on the total research investment for 5 years of $\$ 44,000$ calculated above, it is assumed that the annual expenses amount to $\$ 9,000$. After indexing the fiscal incomes of all years to $1876,{ }^{24}$ it is determined whether the income of an individual year suffices to pay either less than one third of the expenses; between one third and $100 \%$ of the expenses; between one and three times the expenses; between three and six times the expenses; or, finally, more than six times the expenses. The results for the four scenarios are shown in Figure 1. 


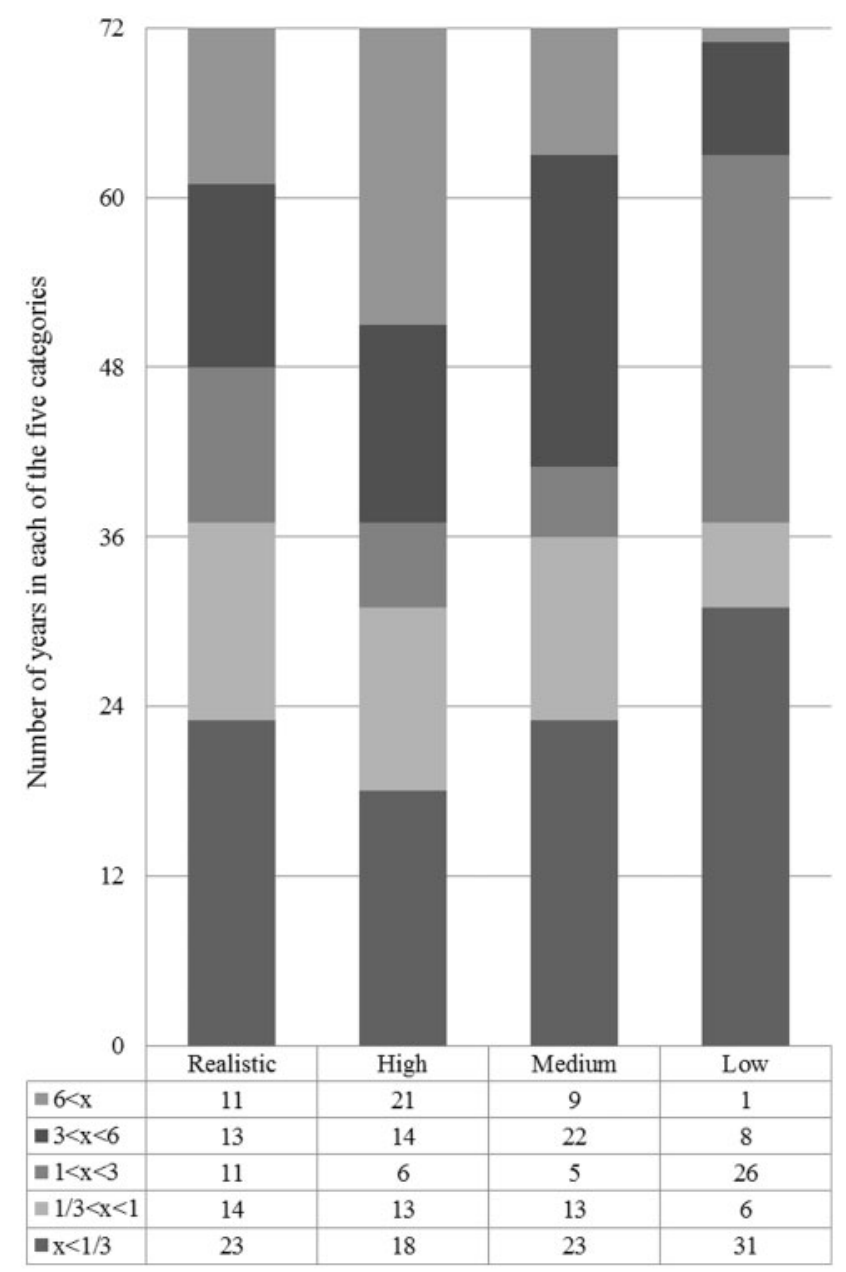

Figure 1. Annual number of research projects fundable with fiscal income from saccharin operations.

In 11 years of the realistic scenario, therefore, the annual expenses of more than six research projects of a similar scale could be financed with the fiscal income flowing from Monsanto's saccharin operations, equating - conservatively calculated - to about 66 'project years' in total. Similarly, in 13 years more than three times the annual expenses of a project could be covered, equating to 39 'project years', and in 11 years, more than one such project could be financed. In total, this means that during the 72 years of Monsanto's saccharin operations the annual research expenses of a similar research project could be covered at least 116 times or, alternatively stated, at least more than 1.5 similarly sized projects could be funded on average every year with the tax payments.

\section{Discussion}

We have demonstrated our research evaluation approach based on tax payments with the example of saccharin. The returns on the fundamental research project, which led to the discovery of saccharin, are quite substantial because they can cover the research expenditures of this project and, additionally, for the expenditures of many (116), similarly sized, projects. Nevertheless, the returns are relatively low compared with rates known from econometric studies and considering the uncertainties involved in fundamental research. In the following, we discuss the factors that influenced the results of the calculations and their importance for the application of our method to other evaluation settings.

Long-term evaluation studies of fundamental research in particular often suffer from problems related to discounting. Significant time lags between the actual discovery and its market introduction - in the example, this lag lasted from 1878 to 1901 -reduce the value of the discounted incomes as well as the IRR, as they represent periods requiring discounting without producing incomes. Furthermore, considering an average product lifecycle, early incomes, which by definition are less heavily discounted, are lower compared with later periods, when the product is established. In the case of saccharin and Monsanto, this effect was very pronounced: firstly, market sales at the turn of the century were rather low; secondly, Monsanto dominated the market only after the mid-twenties; thirdly, tax rates were minimal until World War I. In addition to that, saccharin cannot be considered to be a regular consumer product for many years, as the sales were restricted by the government (see Table 1). Saccharin turnovers in a free market environment probably would have been substantially bigger.

As mentioned in Section 2, the tax-based approach can be conducted on different levels of complexity. Our study on saccharin including only Monsanto's tax payments, on the one hand, allowed for an in-depth examination of the case; on the other hand, this reduced of course the comparability to econometric studies, for instance, which assess entire industries. Still, in future studies, it is possible to apply our method to a set of companies or even to an industry, as detailed in the conclusion below. Regarding other aspects, our calculations are also rather conservative. For instance, the taxes paid by Monsanto's employees, owners, and shareowners, and those of other companies in the value chain (suppliers of raw materials and vendors of saccharin) were not included. Also, import duties on raw materials, saccharin or saccharin intermediates, as well as value added tax were ignored. Going even one step back, a complete valuation would have to include tax income arising from intangible effects of Remsen's research as well, such as knowledge creation beyond saccharin and training of skilled graduates. From a methodological point of view, it is conceivable to include such factors in studies conducted with our approach. However, the determination of their value might involve a series of assumptions and estimations, which would not increase the reliability of such a study.

Of course, as pointed out by David et al. (1992), there are only few new products that completely lack substitutes. When saccharin was commercialized, it was on the one 
hand the first noncaloric synthetic sweetener known, but on the other hand it competed in the 'market for sweetness' with sugar. It is, however, very difficult to estimate the true substitution effect of saccharin consumption. Ballinger suggested that, '[d]ecreased sugar sales probably amounted to less than 100,000 tons in 1965 , although total usage of noncaloric sweeteners [saccharin and cyclamate] was equivalent in sweetness to about 343,000 tons of refined sugar. ${ }^{25}$ Compared with the nine million tons of refined sugar, which were consumed in 1965 in the USA, the substitution effect seems small. During wartimes when sugar was scarce, there was probably no substitution effect at all. In the fifties the discovery of cyclamates showed further that saccharin is not unique, as other research also could lead to a noncaloric sweetener representing a substitute for saccharin. To increase the validity of future studies conducted with our approach, the influence of such substitution effects on the tax payments could be estimated. However, it was beyond the scope of the present research to compare the value of saccharin with all its noncaloric sweetener substitutes, as implied by David et al. (1992).

For the present case, we relied heavily on archival material for our calculations. Despite being an extensive and largely untapped source of data, the associated limitations should be noted. The intentions underlying the creation of a document - e.g. an annual report, meeting minutes, or correspondence-can influence its content and thus the information that is derived from it. To prevent possible biases, we have considered several different sources for our calculations whenever available, making the procedure more laborious. Nevertheless, some fluctuations in our time series might be related to the use of archival material of various kinds. The impact of single fluctuations on the overall result is, however, small. As mentioned in Section 2, it is possible to rely on other data sources for future studies based on our approach. In an ideal case, data obtained directly from companies could enhance the reliability of the calculations. Furthermore, to increase external validity, it would be beneficial to conduct studies on several research projects based on comparable data sources, e.g. corporate data.

The end result of an evaluation study based on our method depends not only on the income generated by the commercialization of an innovation and the sources used to estimate it but also on the associated research expenditures and the setting of appropriate boundaries regarding projects to be included or excluded from the considerations (Marjanovic et al. 2009). Regarding research costs, the focus in the present study was laid on Remsen's group at The Johns Hopkins University, leaving out his previous research in Germany and in Williamstown, MA, as well as complementary research in organic chemistry. However, we included all the initial expenses to furnish his laboratory from scratch, outlays for his entire group - not only for the research leading to 'benzoic sulfinide' - and a period of 5 years, although the compound was discovered already after 2 years. The research costs are therefore reasonably calculated and very unlikely underestimated.

Of course, the investment in Remsen's research does not reflect the total cost involved to arrive at saccharin as a research result - an issue that is not unique to our study. 'Because of the cumulative nature of science, this total investment may have extended over decades or centuries' (Mansfield 1991: 6). However, first of all, at the time Remsen started his research at The Johns Hopkins University, these were sunk costs (ibid.). Secondly, as Griliches (1958) showed, the problem can be reduced ad absurdum when taking more and more past research into consideration. Lastly, the compilation of the benefits is limited as well by focusing on Monsanto's tax payments only, which balances the effect.

The costs associated with the commercialization of a research result are generally not limited to the direct expenses of the research group(s) involved. They include further developmental work and other expenditures contributing to a successful market introduction. These costs need to be considered for studies based on our approach, as long as they were publicly financed. In the case of saccharin, Fahlberg's expenses for the synthesis optimization as well as for the commissioned safety studies should be excluded, as they were compensated by private profits. By contrast, the costs associated with publicly funded safety studies-for instance, the Remsen board-would need to be considered to increase the validity of our study.

Furthermore, it is conceivable that some projects associated with average research costs require aboveaverage investments for commercialization. This could possibly translate into higher sales margins and thus higher returns on the initial research outlays when calculated with our method. However, this fact does not represent a flaw of our approach; private investors will only commit large amounts of resources to commercialization when they can expect high returns. Of course, such high returns are associated with high tax payments and thus higher benefits in regard of the initial research investment.

Finally, it should be mentioned that saccharin was commercialized rather linearly (Warner 2008). Although this might be common in chemistry (David et al. 1992), other innovations are frequently based on knowledge diffusion from several different research areas. Such research can be evaluated with our method as well, but the process might be more complex.

\section{Conclusion}

Herein we have proposed that tax payments accruing from the commercialization of research findings can be 
used to assess the economic returns to publicly funded research. Our method can potentially complement existing tools in future evaluation studies. We have discussed the advantages of our approach - the use of a direct measure, its intuitiveness, the consideration of different levels of complexity, the need of fewer theoretical assumptions compared with other assessment tools and its applicability to different types of researchand described its limitations - only projects that led or will lead to identifiable tax-relevant impacts can be considered.

We have demonstrated the application of our approach with the example of saccharin, and we found a conservatively calculated benefit to cost ratio of more than 10 to 1 and an IRR of more than 7\%. From an annualized perspective, on average more than 1.5 similarly sized research projects could have been sustained in every single of Monsanto's 72 years of saccharin production with the respective tax payments.

Although the case offered a unique long-term valuation perspective, owing to the discovery of saccharin already in 1878 , our study seen individually cannot serve for public accountability purposes, which have gained popularity (Luukkonen-Gronow 1987; Arnold and Balázs 1998). However, future research evaluation studies could benefit from the application of our approach in addition to the established methods, as the latter largely neglected tax payments.

In the context of quantitative evaluations of publicly funded R\&D programs, offices or agencies collect data on the respective research expenses. These data can be used to complement the studies with an assessment of the economic effects with our approach. The strategies to obtain the additionally required information on tax incomes vary depending on the specifics of the programs under evaluation. Cases having broad impacts on many companies or even an entire industry will benefit from the estimations of tax revenues in sector studies. For instance, the economic contributions of the biotechnology industry to the US economy including its tax revenues were assessed by Ernst and Young (2000). By contrast, in cases having specific impacts on a clearly identifiable set of companies, e.g. licensees, the agencies should collaborate with these companies - ensuring confidentiality - to obtain appropriate data. Perhaps the provision of data could even be included in the licensing contracts.

An entire team of evaluators could further pay attention to the aspects neglected in the valuation of saccharin, as mentioned in Section 4 above. Thus, complementing future evaluation studies with our approach could lead to a more complete appreciation of the economic impacts of publicly funded research, as there is no general method, which can take into account all the influences of basic research at once (Tassey 2003).

\section{Supplementary data}

Supplementary data is available at REEVAL Journal online.

\section{Acknowledgements}

The authors would like to thank Miranda Rectenwald (University Archives, Washington University, St. Louis), Jim Stimpert (Sheridan Libraries, The Johns Hopkins University, Baltimore), and the staff at the Textual Research Section of the National Archives II in College Park for providing assistance with the identification of relevant archival records. The research further benefited from discussions with Dr Tobias Straumann, lecturer in economic history (Department of Economics, University of Zurich). Additionally, we would like to thank the referees for their helpful comments to the earlier versions of this article.

\section{Notes}

1. Although Remsen's research was funded by the endowment of Johns Hopkins, he was free to pursue projects satisfying his own curiosity. He was not obliged to consider possible interests of a sponsor. Therefore, it is legitimate to use the saccharin case as a proxy for publicly funded curiosity-driven research.

2. The annual reports are contained in the Monsanto Company Records (MCR) held by the University Archives, Department of Special Collections, Washington University Libraries, St. Louis, MO. Annual reports 1924-49: series 36, box 1; annual reports 1950-63: series 8, box 2; annual reports 1964-72: series 8, box 4. Pre-1924 figures (total assets, total sales) were extracted from: Foristall, T.M. 'The Merit of Monsanto', BARRON'S The National Financial Weekly, 3 July 1933, 6, series 10, box 1, folder Chemical Industry (General History [1900-50]); Monsanto Chemical Company and Subsidiary Companies Financial Data, ca. 1953, series 10, box 4, folder Finance (History); John F. Queeny to A. C. F. Meyer, Cashier, South Side Bank of St. Louis, 18 January 1911, series 10, box 4.

3. In 1904 the three scenarios were not developed according to the general rule described in the text because it is very probable that the capital bound in saccharin production is still very high.

4. Ledgers Sales, Cash Receipts, Mchds Charges, Mchds Credits January 1906-January 301907 and Sales, Cash \& Journal February 1907-January 1908, MCR, series 10 , subseries 2, flat box 33 .

5. 'Annual statement for 1910 shows very satisfactory results. [...] Made $\$ 54,000$ on caffeine with $1 \$$ profit per pound, about $\$ 8000$ each on saccharin and phenolphthalein, $\$ 6000$ on chloral hydrate, small loss on phenacetin, 10,000 loss on vanillin.' Jules Bebie's 
diary, ca. 1911, MCR, series 10, box 5, folder Monsanto Company History (Historical Accounts [Bebie, Jules]).

6. 10 March 1920, MCR, series 14, box 22, folder Queeny, J. F. (scrapbooks [copies of]).

7. As Seater (1982) notes, his excess profit tax rates are weighted averages of graduated rates. As it is not possible to derive the exact rate applicable to Monsanto, the stated average rates are used for the calculations. Thereby, it is not discriminated between normal and excess profits, as the application of the excess tax rate to the entire income still underestimates the total tax burden from 1915 through 1919 (approximately $\$ 910,000$ from our calculations versus more than \$2 million stated in the leaflet 'Information regarding Monsanto for purchasers of Mortgage').

8. These reports can be downloaded from <http:// archive.org/details/syntheticorganic19yyunit $>$ (substitute $y y$ for respective years), last access: 12 July 2013.

9. Ballinger, R.A., United States Department of Agriculture, Noncaloric Sweeteners: Their Position in the Sweetener Industry (hereafter: Ballinger), May 1967, RG 88, box 3978, folder 482 1967, National Archives II, College Park, MD.

10. Falling prices are rather unexpected, as Monsanto was the only US producer beginning in 1925 . However, this might have been a good strategy to render the market unattractive for newcomers or to counter imports. Maybe, the introduction of the insulin therapy in the twenties also influenced saccharin pricing. Later, during the economic downturn, pressure on prices was generally high.

11. A further rationale for a rather high percentage of saccharin sales in respect of total residual flavor sales is the possible underreporting from Monsanto as in the year 1919 .

12. Report in Connection with Renegotiation of War Contracts for the Year Ended December 31, 1942, 1943, MCR, series 10, box 7, folder Monsanto Company History (World War II [Re-negotiation of War Contracts (1942)]).

13. Report in Connection with Renegotiation of War Contracts for the Year Ended December 31, 1942 (resp. 1943), 1943 (resp. 1944), MCR, series 10, box 7, folder Monsanto Company History (World War II [Re-negotiation of War Contracts (1942, resp. 1943)]).

14. A. P. Kroege, List of products of which Monsanto is the major producer, 21 November 1951, MCR, series 1, box 5 , folder Organic Chemicals Division (Sales).

15. Ballinger.

16. 'Sweetness Sans Sucrose', Chemical Week, 13 October 1951, RG 88, box 3978, folder 482 1967, National Archives II.
17. Ballinger.

18. Press release relating to saccharin price cuts, 26 October 1959, MCR, series 3, box 3, folder Saccharin (History).

19. Ballinger.

20. Monsanto, 1962 annual report, 1963, MCR, series 8, box 2 , and press release relating to increased saccharin production capacities, series 3, box 3, folder Saccharin (History).

21. Charles C. Edwards, Commissioner of Food and Drugs, to James J. Delaney, member of the House of Representatives, 25 May 1970, RG 88, box 4609, folder 482 'Saccharin' 1970-March 91972 Vol. I, National Archives II. This estimate was used to calculate Monsanto's 1970 saccharin sales.

22. Press release relating to saccharin price reduction, 5 August 1964, MCR, series 3, box 3, Saccharin (History).

23. The values of the years 1919-72, as well as 1876-99 were discounted using the yields of long-term US government bonds (series Cj1192 in Carter et al. (2006)). The values of the years 1900-18, for which data from US government level is lacking, were discounted using yields of long-term high-grade municipal bonds (series Cj1193), which do not differ substantially from the values in Cj1192 in the years when both are available.

24. The purchasing power index and the gross domestic product deflators published by Officer, Lawrence H. \& Williamson, Samuel H., MeasuringWorth, www. measuringworth.com (last access 30 June 2013), 2011, were used for the calculations, as there is no perfect measure for the values to be indexed. However, the final results of the two methods do not differ substantially, and therefore, only the result obtained with the purchasing power index is shown.

25. Ballinger, iv.

\section{References}

Advisory Council on Scientific Policy. (1960) Annual Report of the Advisory Council on Scientific Policy 1959-1960. London: Her Majesty's Stationery Office.

Arnold, E. and Balázs, K. (1998) Methods in The Evaluation of Publicly Funded Basic Research: A Review for OECD, Brighton, UK, <http://www.technopolis-group.com/resources/downloads/reports/022 eval bas.pdf > accessed 6 April 2010.

Balconi, M., Brusoni, S. and Orsenigo, L. (2010) 'In Defence of the Linear Model: An Essay', Research Policy, 39/1: 1-13.

Beyer, L. (2005) Vom Doktoranden zum bedeutenden Chemiker. Leipzig: Passage Verlag.

Byatt, I.C. R. and Cohen, A.V. (1969) An Attempt to Quantify the Economic Benefits of Scientific Research, Science Policy Studies, 4. London: Her Majesty's Stationery Office.

Carter, S.B. et al. (eds), ed. (2006) Historical Statistics of the United States. Volume 3: Economic Structure and Performance, Millennial edition. New York, NY: Cambridge University Press. 
Chien, S. and Silverstein, S.C. (1993) 'Economic Impact of Applications of Monoclonal Antibodies to Medicine and Biology', The FASEB Journal, 7/15: 1426-31.

Chirelstein, M.A., Day, Langdon and Owens, Elisabeth A. (1963) Taxation in the United States. Chicago: Commerce Clearing House.

David, P.A., Mowery, D. and Steinmueller, W.E. (1992) 'Analysing the Economic Payoffs from Basic Research', Economics of Innovation and New Technology, 2/4: 73-90.

Ernst \& Young. (2000) The Economic Contributions of the Biotechnology Industry to the U.S. Economy, <http://bio.org /speeches/pubs/ernstyoung.pdf >, accessed 22 June 2011.

Forrestal, D.J. (1977) The Story of Monsanto. Faith, Hope and $\$ 5,000$. New York, NY: Simon and Schuster.

Forster, S.P. and Seeger, S. (in preparation a) 'Saccharin beyond serendipity'.

—. (in preparation b) 'Monsanto as a successful start-up from curiosity-driven research'.

Fudenberg, H.H. (1973) 'Fiscal Returns of Biomedical Research', Journal of Investigative Dermatology, 61/6: 321-9.

Geiger, R.L. (2004) Knowledge and Money: Research Universities and the Paradox of the Marketplace. Stanford, CA: Stanford University Press.

Getman, F.H. (1980) The Life of Ira Remsen. New York, NY: Arno Press.

Georghiou, L. and Roessner, D. (2000) 'Evaluating Technology Programs: Tools and Methods', Research Policy, 29/4-5: 657-78.

Griliches, Z. (1958) 'Research Costs and Social Returns: Hybrid Corn and Related Innovations', The Journal of Political Economy, 66/5: 419-31.

Gulbrandsen, M. (2009) The Role of Basic Research in Innovation, < http://www.cas.uio.no/Publications/Seminar/ Confluence Gulbrandsen.pdf $>$ accessed 26 Mar 2010.

Hall, B.H., Mairesse, J. and Mohnen, P. (2009) 'Measuring the Returns to R\&D', NBER working paper series, No. 15622. Cambridge, MA.

Hannaway, O. (1976) 'The German Model of Chemical Education in America: Ira Remsen at Johns Hopkins (1876-1913)', Ambix, 23/3: 145-64.

Hill, J.A. (1913) 'The Income Tax of 1913', Quarterly Journal of Economics, 28/1: 46-68.

Hoppe, H.C. and Pfähler, W. (2001) 'Ökonomie der Grundlagenforschung und Wissenschaftspolitik', Perspektiven der Wirtschaftspolitik, 2/2: 125-44.

IIT Research Institute. (1968) Technology in Retrospect And Critical Events in Science, Volume 1, Chicago, IL.

Jewkes, J., Savers, D. and Stillerman, R. (1969) The Sources of Invention, 2nd edn. London: Macmillan.

Kauffman, G.B. and Priebe, P.M. (1978) 'The Discovery of Saccharin: A Centennial Retrospect', Ambix, 25/3: 191-207.

Kay, J.A. and Llewellyn Smith, C.H. (1985) 'Science Policy and Public Spending', Fiscal Studies, 6/3: 14-23.

Klevorick, A.K. et al. (1995) 'On the Sources and Significance of Interindustry Differences in Technological Opportunities', Research Policy, 24/2: 185-205.

Lichtenberg, F.R. and Siegel, D.S. (1991) 'The Impact of R\&D Investment on Productivity - New Evidence Using Linked R\&D-LRD Data', Economic Inquiry, 29/2: 203-29.

Link, A.N. (1996) 'Economic Performance Measures for Evaluating Government-Sponsored Research', Scientometrics, 36/3: 325-42.

Link, A.N. and Scott, J.T. (2004) 'Evaluating Public Sector R\&D Programs: The Advanced Technology Program's Investment in Wavelength References for Optical Fiber
Communications', The Journal of Technology Transfer, 30/1-2: 241-51.

Linquiti, P. (2012) 'The Importance of Integrating Risk in Retrospective Evaluations of Research and Development', Research Evaluation, 21/2: 152-65.

Luukkonen-Gronow, T. (1987) 'Scientific Research Evaluation: A Review of Methods and Various Contexts of Their Application', R\&D Management, 17/3: 207-21.

Mansfield, E. (1991) 'Academic Research and Industrial Innovation', Research Policy, 20/1: 1-12.

Marjanovic, S., Hanney, S. and Wooding, S. (2009) A Historical Reflection on Research Evaluation Studies, Their Recurrent Themes and Challenges, Santa Monica, CA, <http://www. rand.org/content/dam/rand/pubs/technical_reports/2009/

RAND TR789.pdf $>$, accessed 11 April 2011.

Martin, B.R. and Salter, A.J. (1996) The Relationship Between Publicly Funded Basic Research and Economic Performance, <http://www.hm-treasury.gov.uk/d/156.pdf>, accessed 24 Feb 2010

Martin, B.R. and Tang, P. (2006) The Benefits from Publicly Funded Research, SPRU Electronic Working Paper Series, No. 161 (Falmer, Brighton, UK) <http://www.sussex.ac.uk/ spru/research/sewps $>$ accessed 30 June 2013.

Murphy, K.M. and Topel, R.H. (2003) 'The Economic Value of Medical Research'. In: Murphy, K.M. and Topel, R.H. (eds) Measuring the Gains from Medical Research, pp. 41-73. Chicago, IL: University of Chicago Press.

Narin, F., Hamilton, K.S. and Olivastro, D. (1997) 'The Increasing Linkage Between U.S. Technology and Public Science', Research Policy, 26/3: 317-30.

Noyes, W.A. and Norris, J.F. (1932) 'Biographical Memoir of Ira Remsen, 1846-1927', National Academy of Sciences, Biographical Memoirs, 14: 207-57.

Pavitt, K. (1991) 'What Makes Basic Research Economically Useful?', Research Policy, 20/2: 109-19.

Price, D. de S. (1984) 'The Science/Technology Relationship, the Craft of Experimental Science, and Policy for the Improvement of High Technology Innovations', Research Policy, 13/1: 3-20.

Pyle, J.F. (1922) 'The Income-Tax Law of the State of Missouri, as Amended August 3, 1921', Journal of Political Economy, 30/3: 363-74.

Roessner, J.D. (1993) 'Use of Quantitative Methods to Support Research Decisions in Business and Government'. In: Bozeman, B. and Melkers, J. (eds) Evaluating $R \& D$ Impacts: Methods and Practice, pp. 179-205. Boston, MA: Kluwer Academic Publishers.

Roth, K. and Lück, E. (2011) 'Die Saccharin-Saga', Chemie in unserer Zeit, 45/6: 406-23.

Salter, A.J. and Martin, B.R. (2001) 'The Economic Benefits of Publicly Funded Basic Research: A Critical Review', Research Policy, 30/2: 509-32.

Scherer, F.M. and Harhoff, D. (2000) 'Technology Policy for a World of Skew-Distributed Outcomes', Research Policy, 29/4-5: 559-66.

Schmoch, U. and Schubert, T. (2009) 'When and How to Use Bibliometrics as a Screening Tool for Research Performance', Science and Public Policy, 36/10: 753-62.

Scott, A. et al. (2002) The Economic Returns to Basic Research and the Benefits of University-Industry Relationships: A Literature Review and Update of Findings, <http://citeseerx. ist.psu.edu/viewdoc/download?doi $=10.1 .1 .25$. $2107 \&$ rep $=$ rep $1 \&$ type $=$ pdf $>$, accessed 26 Mar 2010.

Seater, J.J. (1982) 'Marginal Federal Personal and Corporate Income Tax Rates in the U.S., 1909-1975, Journal of Monetary Economics, 10/3: 361-81. 
Seligman, E.R.A. (1970) The Income Tax: A Study of the History, Theory, and Practice of Income Taxation at Home and Abroad, 2nd edn. New York: A.M. Kelley.

Spaulding, H.B. (1927) The Income Tax in Great Britain and the United States. London: P.S. King \& Son, Ltd.

Tassey, G. (2003) Methods for Assessing the Economic Impacts of Government $R \& D,<\mathrm{http}: / /$ reference.kfupm.edu.sa/content/ $\mathrm{m} / \mathrm{e} /$ methods for assessing the economic 87444.pdf $>$ accessed 25 Jan 2011.

Tax Foundation. (2012) Federal Corporate Income Tax Rates, Income Years 1909-2012, <http://taxfoundation.org/article/ federal-corporate-income-tax-rates-income-years-1909-2012> accessed 20 Jun 2013.

United States Bureau of the Census. (1915) Wealth, Debt, and Taxation 1913, Vol. 1. Washington DC: Government Printing Office.

United States Tariff Commission. (1924) 'Census of Dyes and other Synthetic Organic Chemicals 1923', <https://archive. org/details/syntheticorganic1923unit>, accessed 13 Nov 2013.
(1946) 'Synthetic Organic Chemicals: United States Production and Sales 1944', <http://archive.org/details/ syntheticorganic1944unit> accessed 12 Jul 2013.

van Raan, A.F.J. (2000) 'Socioeconomic Impact of R\&D. R\&D Evaluation at the Beginning of the New Century', Research Evaluation, 8/2: 81-6.

Vincett, P.S. (2010) 'The Economic Impacts of Academic Spinoff Companies, and Their Implications for Public Policy', Research Policy, 39/6: 736-47.

Warner, D.J. (2008) 'Ira Remsen, Saccharin, and the Linear Model', Ambix, 55/1: 50-61.

Weisbrod, B.A. (1971) 'Costs and Benefits of Medical Research: A Case Study of Poliomyelitis', The Journal of Political Economy, 79/3: 527-44.

Zellner, C. (2003) 'The Economic Effects of Basic Research: Evidence for Embodied Knowledge Transfer via Scientists' Migration', Research Policy, 32/10: 1881-95. 